\title{
Issues of Teleportation and Personhood in Stephen King's the Jaunt
}

\author{
Prof M.A. Israel A. C. Noletto \\ Piauí Federal Institute \\ IFPI/Anglolit \\ Brazil
}

Prof Dr Sebastião Alves Teixeira Lopes

Piauí Federal University

UFPI/Anglolit

Brazil

Prof Dr Margareth Torres de Alencar Costa

\author{
Piauí State University \\ UESPI/Anglolit \\ Brazil
}

\begin{abstract}
This paper's aim is to provoke thought experiments and a speculative reading on the Science Fiction/horror short story The Jaunt (1985) written by Stephen King, regarding personhood philosophical and moral issues related to its central theme, teleportation. We focus our discussion on two main topics: (1) The philosophical and conceptual implications of teleportation of living beings and the consequent issue of personhood, that is, the so called "duplicate paradox." (2) The reason why conscious or awake living beings cannot survive the jaunt and the repercussions thereof. Such thinkers as Derek Parfit (2016),David J. Chalmers (2016), Eric Olson (2016), among others greatly subsidise our discussion. We also produce a concise comparative analysis of concepts unearthed from the plot that find parallels in the blockbusters Inception (2010) and The Matrix (1999). The result is an extensive exegesis of the text and a broad metaphysical consideration concerning the author's views.
\end{abstract}

Keywords: SF, the Jaunt, Teleportation, Personhood Issues

\section{Introduction}

The Jaunt, horror/Science Fiction (henceforth sf) short story written by famous Stephen King, published in 1981 and republished as a part of the collection Skeleton Crew in 1985, portrays the tragic story of Mark's son, Ricky, who dies after being teleported while still awake in the early $24^{\text {th }}$ century, when the "jaunting" technology has become commonplace allowing humanity to travel instantaneously to any distance where there is a station or a portal installed. This term "jaunt", by the way, is a reference to Alfred Bester's novel entitled The Stars My Destination (1956), in which the term was first used.

Very few themes draw so much attention of avid dreamers, sf fans and writers or filmmakers, and thus it is nothing new. What is more, as recently asserted by David Garner-York (2015), "in the last two decades, quantum teleportation [...] has moved from the realms of sf to tangible reality." It now constitutes "a building block for quantum computing, quantum communication, and quantum network and, eventually, a quantum internet". In spite of the immeasurable distance that now separates today's teleportation possibilities and the technology envisioned by sf writers and filmmakers, the future prospects in the area make the discussion on the moral and factual implications of such means of transportation much more pungent and pertinent.

Many short stories, novels and films have approached the subject in various ways. Most of those put it in a very favourable light, considering it categorically like one of the most awaited scientific innovations in human history (Kaku 307). Perhaps, Star Trek is among the all-time famous instances of the topic, although it was originally just a strategy to save resources and cheapen the episodes (Bendle 54), and despite the fact that the franchise and its numerous spinoffs only approach the issue from its superficial fantastic perspective, leaving untouched and unquestioned the philosophical and moral implications that emerge there from. 
On the other hand, Stephen King's unnerving short story The Jaunt uses mankind's fear of death, time and the unknown to take teleportation to a higher level of metaphysical discussion (Kaku 307). It could be argued that the short story is chiefly about the limits of sustained sensory deprivation on the mind (MartinezConde).However,there are two main debate points emerging from the problematic observed in the plot that we wish to discuss here. Initially, there is the common philosophical objection, known as "the teleportation paradox" and also as "the duplicate paradox", which has to do with the morality and concept of teleportation and how it relates to deep issues on personhood.

That notion is thought to have been first penned by Derek Parfit in 2002, and republished in 2016, whose contributions help a great deal in this paper, while also having been approached by a number of other philosophers and scholars, as David J. Chalmers (2016), Eric Olson (2016), among others. Following up that discussion, we also speculate on the reason why awake biological beings cannot survive the jaunting process, but rather come out dead on arrival or insane and moribund, and thus the story provides just about enough ammunition to guarantee thriving thought experiments on the matter. Regrettably, to this date and to the best of our knowledge, nothing has been written, discussed or properly analysed about The Jaunt, except perhaps for a few scarce and shallow reviews available on the internet. Hence, our investigation focuses mainly on King's plot, parallel works and sparse commentary made by authors about the side topics exhumed from the short story, instead of analytical work published specifically about the text. So from this point on, we look into what has already been noted about these issues.

\section{Philosophical and Conceptual Implications of Teleportation}

Imagine that a person enters a machine, and then pushes a button that starts a process through which a powerful computer scans and records that same person's every cell, molecule and atom. By that process every thought, habit, experience, memory, every detail about that person's body are stored. As a result, the body of that person disintegrates and that information is then transmitted at the speed of light to some other planet, where a replicator, a corresponding portal, theoretically reintegrates that body and form precisely the very same person, with every single detail of his or her body, memory and thoughts perfectly like it was before being transmitted (Parfit 94). This is usually the concept of teleportation as presented in sf books, and as it happens, it also constitutes the notion adopted by King in The Jaunt. The precise nature of what is called teleportation is indeed of paramount importance here. Snowden (56) argues that if one transports an object $O$ from place $P 1$ to place $P 2$, the object that arrives at $P 2$ must be the very same one as that that leaves $P 1$. Or else, that would not exactly be transportation, since the notions of transportation or movement and identity are closely related and linked. As it is, the transportation of an object depends by definition on the continuity in existence of that object.

In view of that, two main issues regarding the technology of teleportation have disquieted the minds of contemporary thinkers: Primarily, while someone gets their body completely disintegrated to an atomic level, does that not mean that they simply cease to exist even if for an insignificantly short period of time? According to the story, the Jaunt took 0.000000000067 seconds to travel a distance of two miles (King 315). Short, but measurable time! In addition, even if one accepts that the person who comes out of the teleportation process alive and well replicates with perfect precision every single characteristic, both physical and mental, and that the result is the undeniable continuity of all the organizational patterns that once constituted the identity of that person; does that suffice for a complete account of one's personhood? That is to say, is the person that gets reassembled by a computer not really just a duplicate?

To begin with, let us consider the first issue in the light of what we find in the short story and what philosophers and scholars have recently concluded. Two instances in the text fuel the debate on the subject of the presumed death of those submitted to 'jaunting'. First, Patty's insistence on asking what had happened to the mice which Carune had experimented with shows her deep concern as to whether or not she would in fact be dying in the teleportation procedure. No matter how Mark tried to avoid answering his daughter's questions, invariably she would return to uttering: "What about the mice Daddy? [...] What happened to the mice?" (King 311) As the narration goes on, Mark tells of the unsettling famous case of Lester Michaelson, a Jaunt researcher who "tied up his wife [...] and pushed her, screaming, through the Jaunt portal at Silver City" (King 317). Michaelson erased each and every one of the hundreds of thousands of possible portals through which his wife might have emerged. His sole objective was to end his wife's life. 
He understood that the Jaunt process of disintegrating Mrs Michaelson's body was in fact killing her, and since there would be nowhere from which she could emerge, this is, in a pragmatic assessment, the final state in which she would ever be: dead.

Michaelson's lawyer offered the innovative defence that his client could not be tried for murder because no one could prove conclusively that Mr. Michaelson's spouse was dead. Nonetheless, he was convicted and executed for murder all the same. He was not convicted for kidnapping or attempted murder, but for murder! That leaves it without a doubt that those who concerned themselves with morals and ethics in the $24^{\text {th }}$ century viewed the body disintegration procedure as analogous to death. In addition, it is relayed in the text that the Jaunt had been used by several dictators to get rid of political dissidents and adversaries.

It was believed that even the Mafia had their own illegal Jaunt-Stations, linked to the central Jaunt computer through their CIA 'connexions', clearly with the objective of killing without leaving any traces of that (King 317). With that being said, we now turn to the second aforementioned issue of this paper.

While elaborating his argument, Parfit demonstrates the inherent problem with the Jaunt, that is, the so-called "teleportation paradox" or "the duplicate paradox":

[...] A replicator produces a perfect organic copy of you. Since the brain of your Replica is exactly like yours, it will seem to remember living your life up to the moment when you pressed the button, its character will be just like yours, and it will be in every other way psychologically continuous with you. This psychological continuity will not have its normal cause, the continued existence of your brain, since the causal chain will run through the transmission by radio of your "blueprint" (Parfit 94).

Can a "blueprint" or a thorough and complete description of someone's personhood really account for that someone's personhood? To some extent, it is possible to say that teleporting a person is very similar to uploading his or her consciousness into a computer, with the only difference being that the teleportation process also involves scanning and recording that person's body, and not just personality's patterns. In that sense, Mark's explanation of how the Jaunt machinery worked points to the following:

Mark smiled. "Computer time," he said. "The data base. That was the only thing that Carune couldn't beg, borrow, or steal. The computer handled the actual particulate transmission - billions of pieces of information. It's still the computer, you know, that makes sure you don't come through with your head somewhere in the middle of your stomach." (King 312)

Along those lines, Chalmers (205) reckons that if it were possible to upload his brain into a computer, would the result be really him? He then proceeds to examining a dichotomy of two opposing views on the question. First, an optimistic one, through which, obviously, the end result would simply be him. Second, a pessimistic outlook through which the end result would not be the same person, but merely a faithful copy of that person on the grounds that instead of removing somebody's consciousness from their brain and then placing it on a hard drive, the upload would just record it and leave the original intact. Exactly like described by Parfit in the quotation above, the upload could even believe to be that person and make others believe that too, and yet it would still be a simple copy.

With a teleportation device, the distinction lies in that the original does get destroyed, nevertheless, the same query remains: what defines personhood? It is true that our bodies today are not entirely the same as they were when we were born. Cells die and new ones replace the dead ones all the time. So how can we know that a person is still the same and not someone else, even in the case of the jaunting process, through which somebody's every cell gets rebuilt? This is the issue risen by the myth of the ship of Theseus, in which all the planks of a ship are gradually replaced over the years. At the same time, a perfect duplicate is being built from scratch (Chalmers 210). That ship is in every aspect identical to that of Theseus, but that begs the question: which one will really be Theseus's ship? Before answering that, let us consider yet another thought experiment.

Suppose that for whatever reason, a team of scientists decide to perform an operation that will culminate in the extraction of a patient's brain while still keeping both brain and body alive and healthy. The brain is then kept in a vat that also happens to maintain contact to the body via wireless mechanisms that even allow the patient to be conscious and active, moving the body around and far from the brain. Consider this: where is the personhood; in the body, in the brain or in both? (Dennett 58-59) Imagine as well that a glitch in the Jaunt machine causes the teleportation to result in the person being reassembled and also a copy to emerge, how would it be possible to tell who is the original and who is the duplicate. 
In other words, if a person is disintegrated, his or her consciousness scanned and uploaded and then is reassembled and has his or her consciousness restored in a new body, freshly reintegrated by a machine that obviously did not use the very same atoms or molecules of that previous body; will the result be that very same person? Following that discussion, Eric Olson (68) mentions the persistence question regarding the problems involving teleportation and personal identity. The persistence question has to do with asking, in effect, what is necessary for the same person to exist at two different times. Said differently, what does it take for a past or future person to be you? Or, granted that every cell in our body is replaced over time, what is it that continues in ourselves that allows us to still be the same person? (Olson 75) Answering these questions is essential in order to verdict whether or not a teleported person is either a copy or still the same person.

Olson (77) goes on by eliciting two distinct visions: (1) psychological-continuity view and (2) brute-physical view. According to the first notion, the person whose psychological patterns (beliefs, memories, preferences, the capacity for rational thought) continue to exist also continues to exist. Following that logic, a teleported person who replicates exactly and perfectly the psychological patterns of his or her self, prior to teleportation is simply the same person. The problem with that idea is that even someone who has never been submitted to teleportation can lose their memory, change their preferences, or even decrease their capacity for rational thought because of various reasons, like an accident, for example. In that case, if a person gets lobotomised, develops amnesia or lives in a vegetating state, does he or she cease to be the same person or even does he or she cease to exist? This does not sound right at all! Let us then turn to premise number two, that is, the brute-physical view. In line with that view, the persistence in existence of a person consists in the continuity of the body (Olson 77).

It seems clear enough that the balance between the two perspectives must more probably represent reality, as the split brain and body case is meant to demonstrate. In both circumstances, as Ray Kurzweil (102) puts it, there is no interruption in the continuity of life, either psychological or physical, which is not the case with teleportation. Therefore, the only conclusion that sounds now plausible enough is that the end result of teleportation is definitely a replica of the original person and that the Jaunt process is nothing else but certain death (Parfit 94-95). The section that follows will conciliate this theory with the plot of The Jaunt.

\section{The Jaunt - A Speculative and Comparative Reading}

“'It's eternity in there', he said, and dropped dead of what was diagnosed as a massive heart attack" (King 315). The story recounts the case of Rudy Foggia, a convicted murderer who was offered a full pardon to submit himself to the teleportation process fully awake. He agreed to the terms, but while he went through the Jaunt alive, he died right after. "His face had not changed in any physical way - it was not lined or jowly or wasted but it gave the impression of great, almost incredible age." The narration also recounts that his eyes turned bulging blankly, his mouth twitching, his hands splayed out in front of him. The death certificate read a massive heart attack as cause of death.

In a similar fashion, at the horror climax of the story, Ricky, out of curiosity fed by the stories told by his father, Mark, chooses not to breathe the anaesthetic and undergoes the Jaunt process awake. The outcome of such a disturbing development is identical in many ways to Foggia's end. The twelve-year-old boy's hair had also turned snow-white, his eyes became incredibly ancient, the corneas had gone a sickly yellow; "a creature older than time masquerading as boy; [...] the old-young legs twitched and quivered" (King 320). At the end of this horrid scene, Ricky utters the following words and then dies: "Longer than you think, Dad! I saw! I saw! Long Jaunt! Longer than you think -".

The same happened every time any living being was jaunted while still conscious. For instance, Carune's mice always died of unknown reasons when teleported awake. An explanation for that is given in some parts of the text: "In some cases, the act of reemerging had actually seemed to shock them to death" (King 316). What is more, based on all the experiments with animals, including the mice, Mark is drawn towards the conclusion that "while the Jaunt is almost instantaneous physically, it takes a long, long time mentally." To which Ricky, proving to be a prodigious child promptly responds: "It isn't just teleportation, is it, Dad? It's some kind of time-warp" (King 318). Assuming for a moment that Ricky gets it right; let us have a look at the underlying concepts of timewarp. In plain words, Einstein's relativity theory points that space and time are dynamic and curved, thus can be distorted or dilated, making wormholes possible - "tubes of space-time that connect different regions of space and time" (Hawking 135). Transmitting matter, then, through space in a speed analogous to the speed of light, as it is described in The Jaunt, is only possible if through a hypothetical wormhole (Hawking 136). 
Accordingly, we can come up with one final question regarding that: Why is it that the act of re-emerging shocks people to death, when they are conscious? First, it is possible to state that the reason for that does not go far from the reason why patients are administered with anaesthetics before a surgery. Just as cutting open someone's chest while they are still conscious would be unbearably painful, it seems obvious to suppose that disintegrating a person's body to an atomic level would be fatally excruciating, and though that pain would be paused during the Jaunt, the reflections thereof would resume as the body is reintegrated, and as the memories of pain are given to the new brain. The consequences of such a trauma to anyone's mind can only be catastrophic. The same can be said of the subject's heart. The organ receives all the hormonal responses of the brain's activities quite instantly, and thus could not survive such a throbbing experience.

No one in the short story attempts on guessing how long the journey actually lasts in the mind of travellers who are still awake. Based on the situation in which survivors are left, we can only suppose it is too much time for anyone to bear with no input to their minds. The metaphysics of the universe of King's story gives the impression that consciousness is some sort of extracorporeal thing, something independent of the physical brain's activity: "it remains whole and constant" (King 318).

This is a quasi-religious concept, and since it appears to be only an assumption shared by the characters, and not really the cause given by the author, based on Mark's allegation, "even now no one really knows, Patty" (King 318), there must be something else to it, and so we will take the liberty to try and produce a reasonable parallel explanation for such phenomenology.

We shall begin by asserting that there is no evidence whatsoever to support that, in reality, consciousness exists extracorporeally or independently of a physical brain; at the same time, it is also possible to claim that neither is there in the book. Having stated that, we shall turn our discussion back to Ricky's supposition about the Jaunt. Time is relative. It is not an extraordinary thing that mind and body can experience the passing of time differently. When doing something pleasant, for instance, it is not uncommon that the body gets tired and the mind still longs for more, or, for that matter, the other way around.

It sounds plausible to compare this peculiarity of the plot with the blockbuster Inception (2002) written and directed by Christopher Nolan. In the motion picture, a gang of professional dream thieves are forced to create dreams within dreams in order to infiltrate a victim's mind and plant an idea. By the end of the film, we can see three different dream levels plus the figurative Limbo - a possible permanent state of consciousness. Garcia (223) points out that the period of time at each new dream level is multiplied by twenty in relation to time perception in real life. Disserting on Limbo, the deepest level of consciousness, Garcia (224) indicates that the extent of time in dreams tends to infinity. In the scene in which Saito (Ken Watanabe) gets shot, and Cobb (Leonardo DiCaprio), Eames (Tom Hardy), Arthur (Joseph Gordon-Levitt) and Ariadne (Ellen Page) are arguing on the circumstances regarding the dream they are in, Yusuf (Dileep Rao) says that in Limbo time can be unlimited, the chronological sequence can be interminable; what is more, Limbo is also described by Arthur as "raw, infinite subconscious" (Nolan 1:09:00). Otherwise speaking, time perception can be altered by the mind. This is exactly the point at which The Jaunt (1985) and Inception (2002) are most similar. The dichotomy of two separate temporalities, a mental and a physical one. In the short-story the physical temporality is represented by the time it takes for a body to be teleported, but the mind is not linked to this sort of temporality; that is why it has to be knocked down by anaesthetics. In the film, this kind of temporality is represented by real life. The second type is the mental temporality in King's text and the dream temporality in Nolan's movie (Garcia 227).

Just as in Inception, a mind numbed by too many layers of dreams ends up in Limbo, an unparticulated mind, fully aware of the process of death carried out by the jaunting procedure, goes insane because of the amount of perceived time it has the impression of having. It is a matter a few decimals of seconds in reality, but the mind has the ability to warp time both at the beginning of the teleportation and at the end. For both Foggia and Ricky, time felt like eternity. Human mind cannot comprehend eternity, since we are finite beings whose lives actually stretch only for some years. A mind with infinity to itself, with total sensory deprivation, no contact to outside itself, having only what it accumulated over a few decades or less to feed it with thought. It is not hard to imagine that after a certain time, there would be nothing else to think about, no timeline on which to organise memories; only fear and terror, much worse than a castaway on a desert island. At such point, the mind would be in Limbo, just like in Inception, according to Mark's confabulations right before the Jaunt starts: Your mind can be your best friend; it can keep you amused even when there's nothing to read, nothing to do. But it can turn on you when it's left with no input for too long. 
It can turn on you, which means that it turns on itself, savages itself, perhaps consumes itself in an unthinkable act of auto-cannibalism. How long in there, in terms of years? [...] how long for the unparticulated consciousness? A hundred years? A thousand? A million? A billion? How long alone with your thoughts in an endless field of white? And then, when a billion eternities have passed, the crashing return of light and form and body. Who wouldn't go insane? (King 318-319)

But how about the super accelerated aging process that takes on the conscious traveller's body as well? There is another film that presents an interesting idea that can shed some light as to the answer to that question. In The Matrix (1999), at the moment when Neo (Keanu Reeves) is training to learn how to jump between tall buildings, and he falls to the ground, failing to complete the jump safely, he gets hurt. When he gets pulled out of the simulation programme, he notices his mouth is truly bleeding a little.

He then inquires Morpheus (Lawrence Fishburne) as to why he got hurt, since he was in a simulation rather than in real life, to which Morpheus replies: "Your mind makes it real!" (Wachowski and Wachowski 55:27) A similar situation is experienced by Neo's colleagues who die when Cypher (Joe Pantoliano) pulls their plugs, while they are still connected to the matrix. Their minds made their deaths real, though their bodies were in impeccable shape. That is staggeringly similar to the mouse conditions from Carune's experiments that Mosconi dissected: "The initial result was not very encouraging; so far as Mosconi could tell, the mouse he had opened up was perfectly healthy except for the fact that it was dead" (King 307). That is also our premise with the deaths of those who submitted themselves to the Jaunt while conscious. Their bodies die at the disintegration; their minds are fully aware of that. When they are reassembled and their memories are restored, their minds simply remember they died, and as a result, they die once again and for all. Put differently, people had to be put to sleep so that their minds could not realize they were actually dying.

\section{Conclusion}

The issues regarding personhood that teleportation theories generate are left open, inconclusive, and at the same time hidden. King only leaves some clues that might or not lead the audience towards the answers to all the questions that the plot incites. And that is precisely the result of the reading of The Jaunt, incitation to debate about the unnerving nature of the text. Although, the matters that we addressed here may appear to some to be side-issues that are raised by the discussion of the topic of teleportation, and not directly by the text, even granted that King's writings have been attributed a sort of commercial ambition given the fact that they sell really well, we find it hard to believe that King's aim is just that of amusing his audience, and not also of promoting awareness on the theme, which he presents.

King demonstrates a very pessimistic view of technology in his short story. Contrarily, both in literature and predominantly in the cinema, teleportation is often shown devoid of its probable negative concerns. The text depicts people that have already grown accustomed with such technology and thus no longer question the consequences it may bring or the moral collapses it may present. Only a few individuals demonstrate some disquiet as to the real nature of the disintegration of bodies and its consecutive death. Patty, Mark's daughter, driven by juvenile innocence, fear and curiosity, is one of the rare individuals that dare oppugn the use of such a commonplace machinery amidst an ocean of conformist people. Mark and Marilys, his wife, as adults, are of that kind and quickly accept what the futuristic society has already imposed as irrefutable truth, hence feeling the urge to acquiesce to the opinion of the majority. Ricky, sadly, is compelled by boyish inquisitiveness and inconsequentiality to venture on the fatal experience of jaunting still awake in search for knowledge, as a kid that he is, always asking more questions. It is crystal clear that the very same characteristics are found today in technologically advanced societies. Following the sf propensity, The Jaunt has confirmed its power to introduce important reflections.

Most of what we have discussed here is about extrapolation of the problematic approached by the author. It seems like a writing strategy or style of King's to hide the main discussion points of his stories. He does not take much time to elaborate explanations or to work around elicitations. Most of the terror is implicit, and only comes to mind after reading the story while digesting all the information and meditating on the implications and consequences of everything. It is in itself a thought experiment that requires the audience to really think about what is happening. Whereas we do not claim to have conclusively resolved those questions, we have certainly added up to the debate. 


\section{Works Cited}

Bendle, M. (2002). Teleportation, Cyborgs and the Posthuman Ideology. Social Semiotics, 12(1), pp. 45-62. Retrieved 01 24, 2018, from https://www.researchgate.net/publication/249014661_Teleportation_Cyborgs_and_the_Posthuman_Ideol ogy

Chalmers, D. (2016). The Singularity: A Philosophical Analysis. In S. Schneider (Ed.), Science Fiction and Philosophy - From Time Travel to Superintelligence (2nd ed., pp. 171-224). Malden: Wiley Blackwell.

Dennett, D. (2016). Where Am I? In S. Schneider (Ed.), Science Fiction and Philosophy - From Time Travel to Superintelligence (2nd ed., pp. 57-68). Malden: Wily Blackwell.

Garcia, I. (2011). Where Time Stands Still. In T. Botz-Bornstein (Ed.), Inception and Philosophy: Ideas to Die For (1st ed., pp. 217-230). Chicago: Open Court.

Garner-York, D. (2015, October 1st). Why 'Teleportation' is no longer Science Fiction. Retrieved January 25, 2018, from http://www.futurity.org/teleportation-reality-1015872/

Hawking, S. (2001). The Universe in a Nutshell (1st ed.). London: Bantam Press.

Kaku, M. (2008). Physics of the Impossible - A Scientific Exploration into the World of Phasers, Force Fields, Teleportation, and Time Travel (1st ed.). New York: Doubleday.

King, S. (1985). The Jaunt. In Skeleton Crew (1st ed., pp. 287-321). New York: Pocket Books.

Kurzweil, R. (2016). Who Am I? What Am I? In S. Schneider (Ed.), Science Fiction and Philosophy - From Time Travel to Superintelligence (2nd ed., pp. 99-103). Malden: Wiley Blackwell.

Martinez-Conde, S. (2013, May 04). Neuroscience in Fiction: Stephen King's The Jaunt. Retrieved February 7, 2018, from Scientific American: https://blogs.scientificamerican.com/illusion-chasers/the-jaunt/

Nolan, C. (Director). (2010). Inception [Motion Picture]. USA: Warner-Bros.

Olson, E. (2016). Personal Identity. In S. Schneider (Ed.), Science Fiction and Philosophy - From Time Travel to Superintelligence (2nd ed., pp. 69-90). Malden: Wiley Blackwell.

Parfit, D. (2016). Divided Minds and the Nature of Persons. In Science Fiction ans Philosophy (pp. 91-98). Malden: Wiley Blackwell.

Snowden, P. (2012). What Happens to Brundle? Problems of Teleportation and Personal Identity in The Fly. In S. Riches (Ed.), Philosophy of David Cronenberg (1st ed., pp. 53-65). Lexington: The University Press of Kentucky.

Wachowski, L., \& Wachowski, L. (Directors). (1999). The Matrix [Motion Picture]. United States of America. 